\title{
4
}

\section{The Impact of Evidence-Based Medicine in Thoracolumbar Trauma}

\author{
Joseph L. Petfield, James P. Lawrence, Jeffrey Rihn, Eric B. Harris, Alexander R. Vaccaro, \\ and Christopher M. Bono
}

The past few decades have seen remarkable advancement in the evaluation, treatment, and rehabilitation of injuries to the spine and spinal cord. The development of new surgical techniques, imaging modalities, diagnostic classification systems, and biological materials gives cause for hope of improved patient outcomes following spinal trauma. Despite this progress in the understanding and treatment of thoracolumbar trauma, the topic remains one of considerable controversy.

Historically, advances in spine surgical care were introduced to clinical practice without definitive empirical proof of improved clinical outcomes. ${ }^{1}$ Evidence-based approaches to the treatment of thoracolumbar spinal trauma are becoming increasingly prevalent as physicians, patients, and policy makers seek scientifically grounded data of improved and cost-effective patient care. Evidence-based medicine (EBM) is defined as "the conscientious, explicit, and judicious use of current best evidence in making decisions about the care of individual patients."

Evidence-based medicine is not merely the use of the latest clinical evidence, but rather the integration of this information with clinical expertise, critical judgment, and the patient's individual needs. ${ }^{3}$ Such a realistic evidence-based approach is currently being applied to answer important clinical questions, such as the effect of early versus late surgical decompression on neurological recovery, as well as the comparison of operative versus nonoperative treatment in thoracolumbar fractures. ${ }^{4}$ Moreover, evidence-based techniques are also being utilized to validate the development of new surgical interventions. Large, multicenter clinical trials are under way to definitively address the important questions regarding thoracolumbar spine trauma, a field whose research has been characterized as persistently lacking statistical power. ${ }^{4,5}$ This chapter addresses the contributions of EBM over the last few decades on a variety of treatment aspects of thoracolumbar trauma.

\section{Initial Treatment and Examination of Thoracolumbar Trauma}

The acute treatment of trauma and potential spine injuries has undergone a radical transformation over the last 30 years. Prior to the 1970s, the specifics and organization of trauma care varied widely by location and provider. Most initial care was not based on evidence of efficacy, but rather upon local expert opinion. Landmark studies in the 1960s and '70s recognized accidental death and injury as a long neglected cause of preventable death that lacked a body of strong empirical data. ${ }^{6-8}$ As trauma care grew to become an issue of national importance in the United States, states developed uniformly organized, regionally based trauma care systems that showed definitive evidence of improved outcomes. ${ }^{9,10}$ This widespread reorganization of trauma care has resulted in more efficient resource utilization, more targeted clinical care, and improved patient outcomes.

Regional trauma care decreases patient mortality by minimizing the duration of prehospital treatment, directing the transport of patients to designated, accredited specialty trauma centers, and allowing the pooling of resources to provide more cost-effective, efficient treatment (Fig. 4.1). ${ }^{11}$ Specifically regarding spinal cord injury (SCI), clinical evidence has demonstrated that patients sustaining an $\mathrm{SCI}$ demonstrate fewer complications and improved outcomes when cared for by a specialist management system. ${ }^{12,13}$ Regionalization of spine trauma care to designated centers has also facilitated the organization of much-needed large, multicenter, randomized trials investigating spine injury. There are currently 13 designated centers for the treatment of spinal cord injury in the United States.

The acute, prehospital care of potential SCIs is currently under reevaluation. Spinal immobilization following primary spine trauma, although widely recommended, has not been definitively proven to prevent subsequent secondary spine injuries. ${ }^{14,15}$ Moreover, spine immobilization is painful and can 


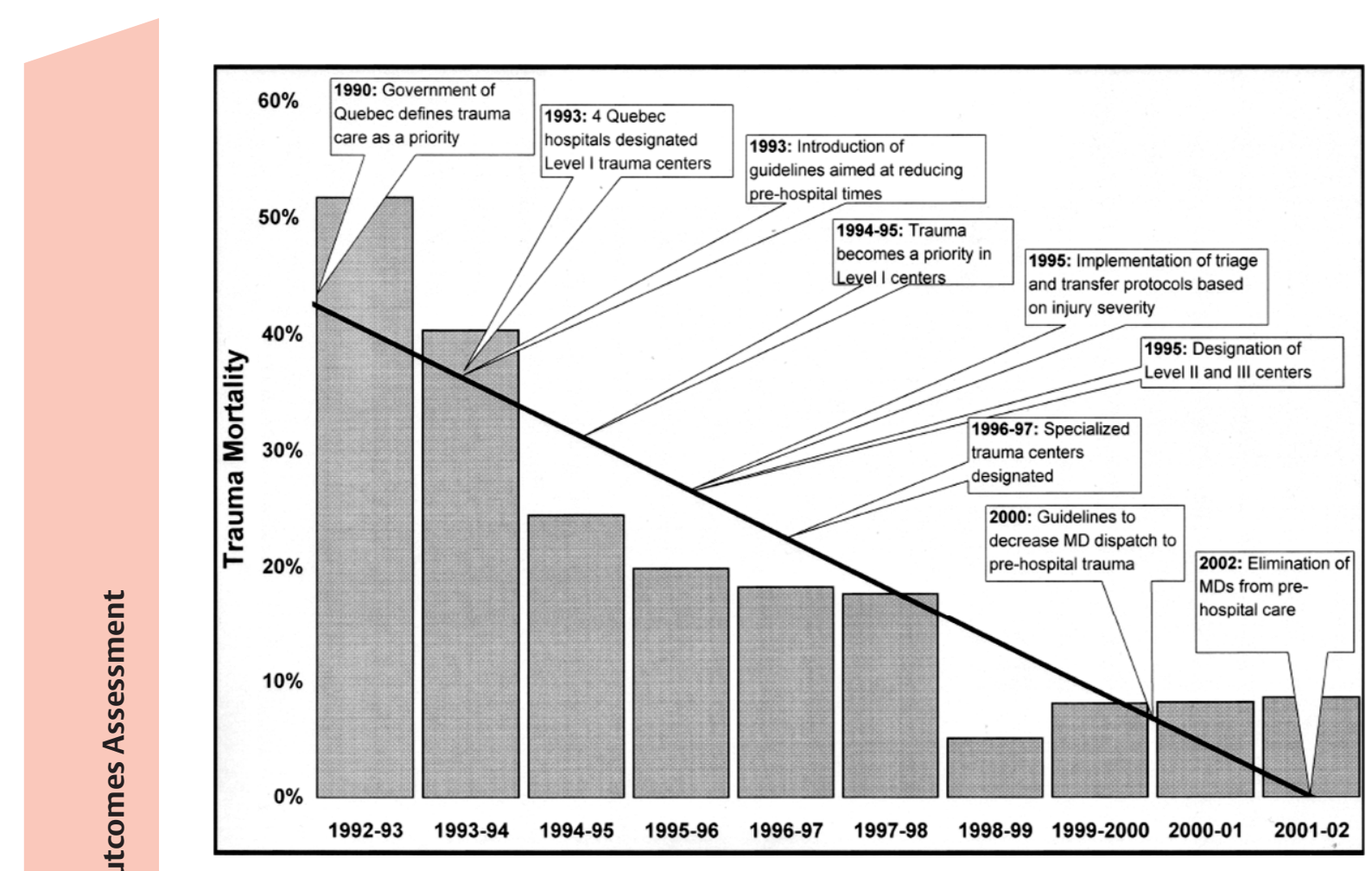

Fig. 4.1 The impact of the regionalization of trauma care on mortality of severely injured patients. (From Liberman M, Mulder DS, Lavoie A, Sampalis JS. Implementation of a trauma care system: evolution through evaluation. J Trauma 2004;56:1330-1335. Reprinted with permission.)

result in several potentially unnecessary complications in the trauma patient. ${ }^{16}$ Definitive research, if feasible, is indicated to identify trauma patients appropriate for immobilization, as well as when and how this immobilization is applied. Clearly, distinguishing between stable and unstable injuries requiring immobilization in a field setting is quite challenging.

There has been a near quantum leap in diagnostic imaging over the past 30 years. The radiographic diagnosis of acute spine trauma has evolved in similar fashion, as sophisticated imaging technology has become more available, more rapid, and less costly. ${ }^{4,17}$ In many centers, helical computed tomographic scanning has replaced plain radiography in the initial evaluation of the spine in the blunt trauma patient because of its greater sensitivity as a screening tool, decreased

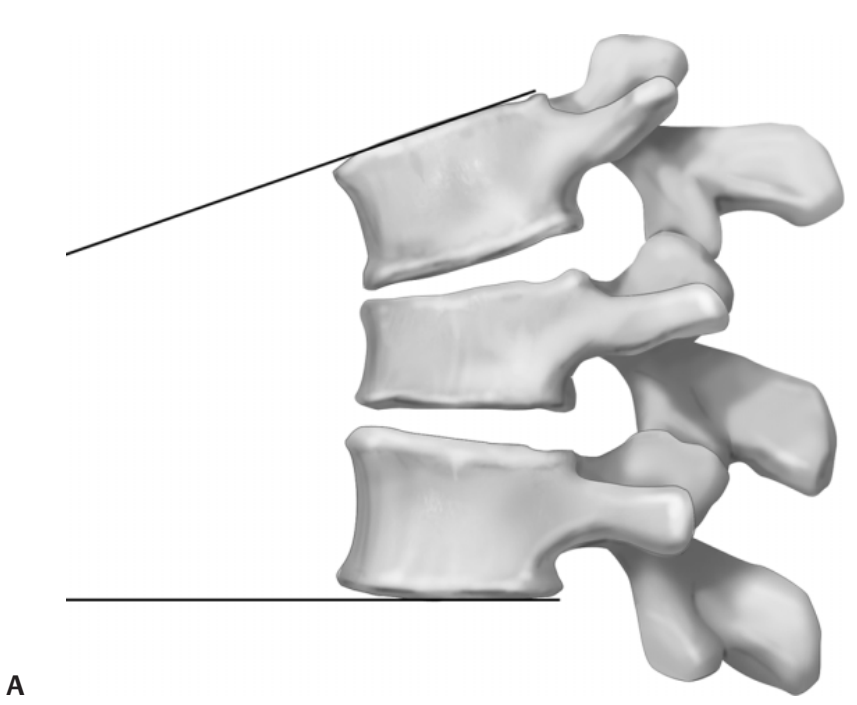

overall cost, and potentially decreased total radiation exposure to the patient. ${ }^{18}$ Magnetic resonance imaging (MRI) has also become an essential tool in the evaluation of the spineinjured patient because it allows for sensitive visualization of injuries to the intervertebral disk, the bony structures, the posterior ligamentous structures, and the neural elements themselves.

A lack of standardization of radiographic measurement parameters used to assess thoracolumbar fractures has complicated both patient evaluation and the reporting of clinical outcomes in the spine literature. A recent systematic review of the literature was conducted by the Spine Trauma Study Group with the purpose of standardizing radiographic interpretation and reducing observer variability (Fig. 4.2). ${ }^{19}$

Fig. 4.2 The recommended radiographic parameters to depict the properties of the injured spinal column. (A) The Cobb angle to assess sagittal alignment. (B) The vertebral body translation percentage to express traumatic anterolisthesis.

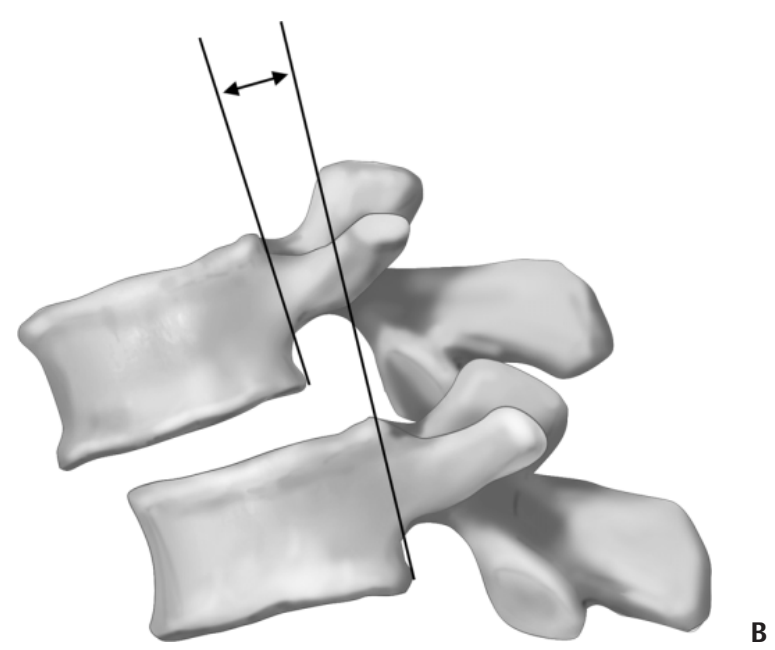



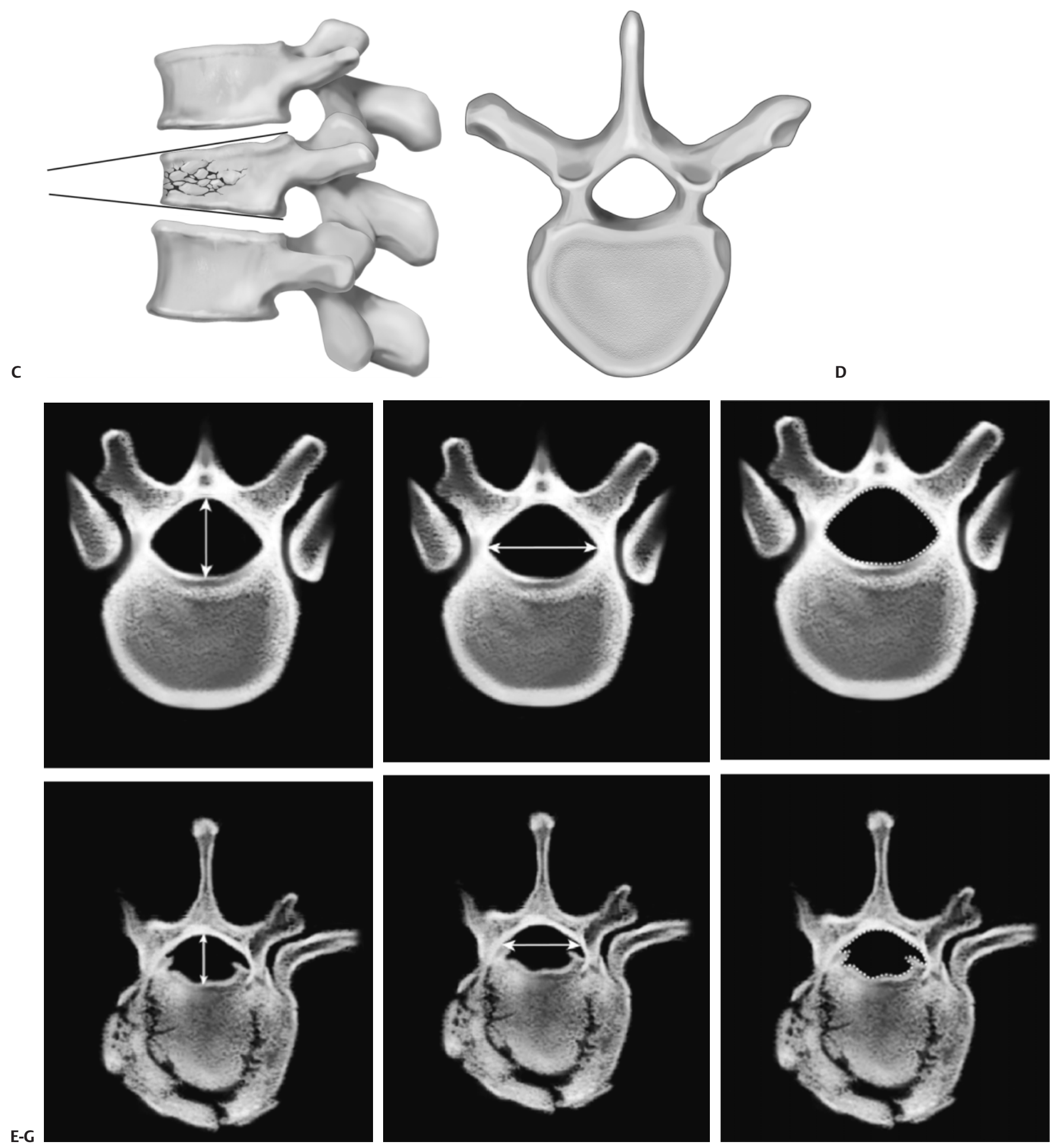

Fig. 4.2 (Continued) (C,D) Anterior vertebral body compression percentage to assess vertebral body compression. (E,F) The sagittal to transverse canal diameter ratio. (G) Canal total cross-sectional area (measured or calculated). (From Keynan O, Fisher CG, Vaccaro A, et al.
Radiographic measurement parameters in thoracolumbar fractures: a Group. Spine 2006;31:E162-E163. Reprinted with permission.) systematic review and consensus statement of the Spine Trauma Study

\section{$\checkmark$ Evidence-Based Classification Systems of Thoracolumbar Injury}

Clinical classification systems can serve several purposes. Ideally, they facilitate accurate communication between treatment providers, provide insight into injury severity and morphology, guide treatment, and promote consistency in clinical research. In the field of thoracolumbar spinal trauma, several classification systems have been developed with these goals in mind. However, there is not currently a definitive classification system that has been clinically proven to be consistently valid and reliable..$^{20,21}$ The Thoracolumbar Injury 
Classification and Severity Score (TLICS) represents the first attempt at validating a thoracolumbar fracture classification system in a scientific manner. ${ }^{22}$

Beginning with Böhler's research of spine fractures in the 1930s, no less than six thoracolumbar injury classification systems have been devised. ${ }^{23-29}$ The most popular classification system used currently in North America is the Denis system, based on his model of the three-column spine. ${ }^{27}$ This system defines four major categories of injury with $16 \mathrm{sub}$ groupings and relies mainly on the condition of the middle column to define fracture severity and predict neurological risk. Recently, the intraobserver and interobserver reliability of the Denis system has been shown to be relatively low. ${ }^{20,21}$ Evidence has also shown that the stability of the middle column of the spine is not the most integral factor of injury severity.

The alternative system currently in use is the AO system proposed by Magerl and colleagues. ${ }^{28}$ This so-called comprehensive system uses a large number of classification steps to precisely define the injury in question. It is perhaps this complexity that contributes to the limited intra- and interobserver reliability cited for the AO system..$^{20-22}$

The Spine Trauma Study Group's (STSG's) TLICS is the most recent attempt at devising a clinically reliable and valid system. Originally proposed as the Thoracolumbar Injury Severity Score (TLISS), ${ }^{30}$ and modified to become the TLICS, ${ }^{22,31,32}$ this classification system presents a scoring mechanism to be used by care providers to assist in the decision between operative and nonoperative treatment. This scoring system is based on three variables corresponding to the spinal injury: the morphological appearance of the fracture, the integrity of the posterior ligamentous complex, and the patient's neurological status (Fig. 4.3). Follow-up studies have found this classification system to have a moderate degree of reliability in classifying thoracolumbar fractures, but a high degree of intra- and interobserver reliability when predicting physician's treatment decisions. ${ }^{33-35}$ Audigé and colleagues recently outlined a three-phase process by which classification systems can be clinically validated. ${ }^{36}$ To date, the TLICS has completed the first two phases, which consist of development and initial multisurgeon studies. ${ }^{22}$ The third phase consists of large, multicenter clinical studies, which are currently in development.

\section{Influences of Evidence-Based Medicine on Surgical Decision Making and Surgical Treatment of Thoracolumbar Trauma}

\section{Surgery or Conservative Treatment}

Immediate thoracolumbar spinal surgical treatment is indicated in patients with unstable fractures, spinal cord compression, and the presence of neurological deficit. ${ }^{37-40}$ Surgical versus nonsurgical treatment of thoracolumbar burst fractures, however, remains a controversial issue because several welldesigned studies exhibit conflicting results. ${ }^{41-44}$

In a prospective, randomized trial of 53 patients with a thoracolumbar fracture without neurological deficit, Wood et $\mathrm{al}^{43}$ found no difference in functional outcome between patients managed operatively or nonoperatively with a body cast or orthosis. In a second prospective, randomized trial on this issue, Siebenga et al ${ }^{42}$ reported significantly better results when treating AO type A3 spine fractures with posterior short-segment transpedicular screw fixation when compared with bed rest and an orthotic device.

Although both of these studies represent a step toward evidence-based clinical decision-making for the treatment of thoracolumbar burst fractures, larger studies with greater statistical power are needed to provide definitive treatment guidelines. However, the execution of such trials is complicated by the difficulty of randomizing injured patients to conservative care in what constitutes a complex ethical scenario. More importantly, the key factor in the stability of thoracolumbar burst fractures appears to be the integrity of the posterior ligamentous complex (PLC). ${ }^{41}$ Thus clinical equipoise exists only for those patients believed to have an intact PLC complex, which is the group that can be ethically randomized to operative versus nonoperative treatment.

\section{Timing of Decompression and Stabilization}

The timing of decompression or fixation following traumatic thoracolumbar injury has been a subject of considerable debate. Experimental evidence in animals indicates that immediate surgical decompression following fracture can be effective in minimizing secondary injury to the spinal cord resulting from inflammatory mechanisms and ischemia. ${ }^{45,46} \mathrm{~A}$ recent meta-analysis of both cervical and thoracolumbar spine injuries has suggested that surgical decompression performed within 24 hours of initial injury demonstrates better neurological outcome in patients with incomplete spinal cord injury when compared with late operative or conservative management. ${ }^{47}$ Although a definitive, high-quality, multicenter, randomized trial is yet to be published regarding early versus late decompression, a recent evidence-based review of the literature by Fehlings and Perrin reviewing cervical spinal cord injuries suggests that surgical decompression should be performed as soon as possible, preferably within 24 hours of injury. ${ }^{46}$ Similar evidence for decompression in the setting of thoracolumbar trauma with neurological deficits is lacking.

Yet clinical studies have not shown that early stabilization or fixation (within 72 hours of injury) demonstrates any benefit regarding neurological outcome. Despite this, nonneurological outcomes have been shown to improve. Various studies have shown that early thoracic and lumbar spine stabilization is associated with significant decreases in intensive care unit (ICU) and hospital length of stays, shorter use of a mechanical ventilator, as well as a decreased incidence postoperative pneumonia and deep venous thrombosis. ${ }^{40,48-51}$ Ideally, a prospective, randomized, controlled trial would be necessary to provide definitive recommendations for early surgical interventions in thoracolumbar fractures.

\section{Advancements in Surgical Instrumentation}

Great advancements have been made in the surgical treatment of thoracolumbar trauma over the past 30 years. Increasingly sensitive and specific imaging modalities have allowed for an improved ability to identify and localize the patterns of injury to the spinal column and the neural axis. This allows a more complete understanding of the morphology of the injury and more detailed preoperative planning. 

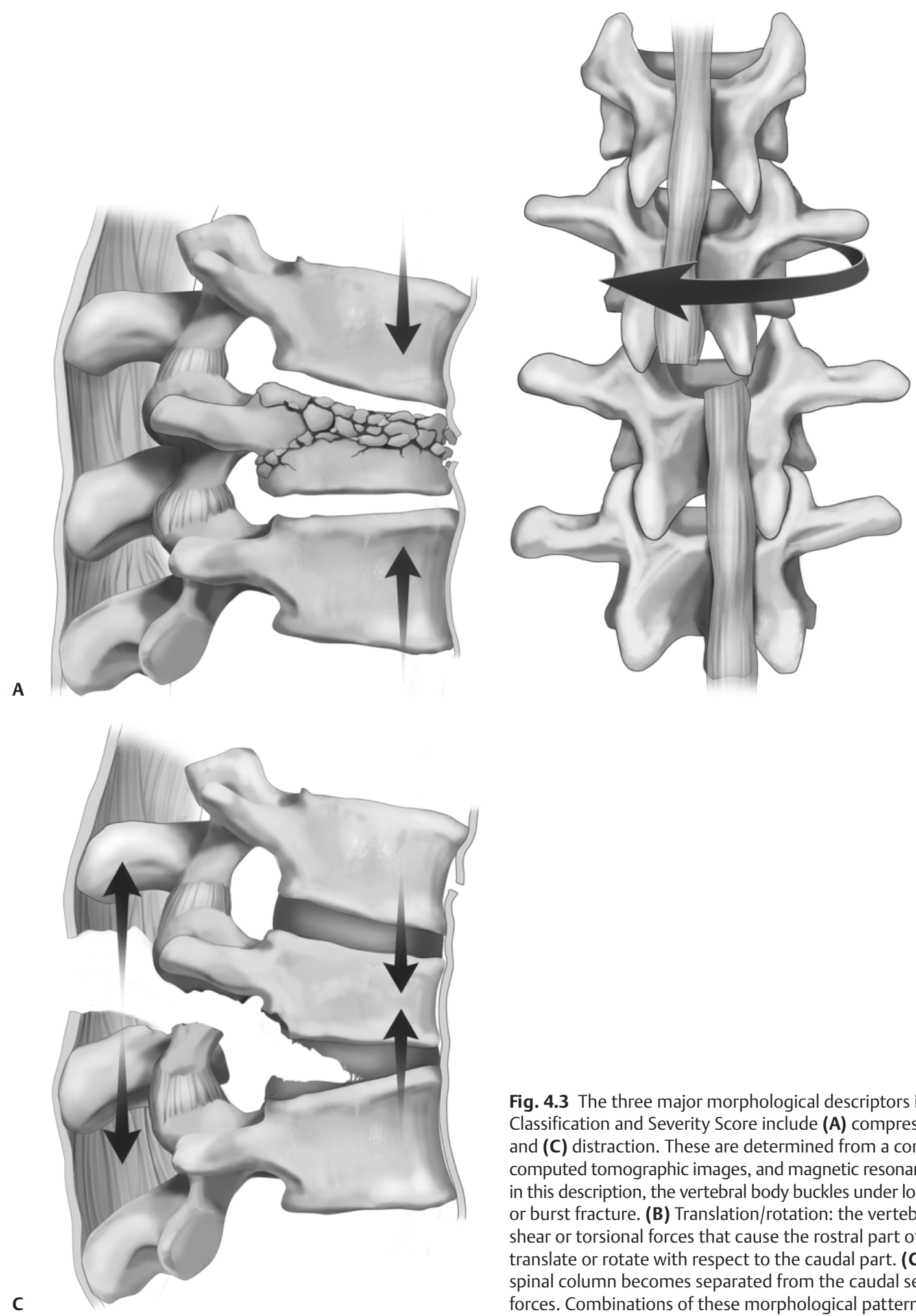

Fig. 4.3 The three major morphological descriptors in the Thoracolumbar Injury Classification and Severity Score include (A) compression, (B) translation/rotation, and (C) distraction. These are determined from a combination of plain film, computed tomographic images, and magnetic resonance imaging. (A) Compression: in this description, the vertebral body buckles under load to produce a compression or burst fracture. (B) Translation/rotation: the vertebral column is subjected to shear or torsional forces that cause the rostral part of the spinal column to translate or rotate with respect to the caudal part. (C) Distraction: the rostral spinal column becomes separated from the caudal segment because of distractive forces. Combinations of these morphological patterns may occur.

When surgery is required, continually evolving operative techniques and the availability of specialized instrumentation, such as pedicle rod and screw fixation systems, have enabled surgeons to more aggressively pursue the goal of stability to the injured spine.

A systematic review conducted in 2004 by Verlaan et al represents one of the first major evidence-based attempts to directly compare the various surgical treatment options for thoracic and lumbar spine fractures. ${ }^{52}$ The review analyzed studies of five major surgical techniques: posterior short-segment instrumentation, posterior long-segment instrumentation, posterior short- or long-segment instrumentation, anterior instrumentation, and combined anterior and posterior instrumentation. Inequalities of the preoperative condition for prospective surgical therapies rendered their direct comparison impossible. However, it was found that no currently used surgical technique was able to maintain the corrected angle of spinal kyphosis. Partial neurological deficit had similar potential to 
resolve irrespective of the choice of operative treatment. The surgical treatment of thoracic and lumbar traumatic fractures was found to be safe and effective, with a low rate of serious complications.

\section{Vertebroplasty and Kyphoplasty}

Vertebroplasty and kyphoplasty for thoracolumbar fractures have recently drawn considerable attention regarding outcomes, potential complications, and indications. The increasing mean age at injury of spinal fractures, higher proportion of patients over 60 years of age, and rising prevalence of osteoporosis in women strongly suggest that scrutiny of these procedures will only increase over time. ${ }^{4,53}$

A prospective study published in 2006 by Álvarez et $\mathrm{al}^{54}$ found that, compared to a nonrandomized, nonoperative cohort, percutaneous vertebroplasty (PV) was shown to be more effective at rapidly reducing pain and improving quality of life of patients suffering from osteoporotic vertebral fractures. However, these differences disappear after 6 months Similarly, a recent systematic review ${ }^{55}$ found that vertebroplasty and kyphoplasty provide short-term pain reduction effectiveness and have a relatively low rate of complications. Leakage of polymethylmethacrylate was found to be the most commonly occurring complication. Though this is usually asymptomatic, its potential neurological consequences are cause for further research. ${ }^{56}$

More recently in 2009, two prospective randomized controlled trials ${ }^{57,58}$ found that in the treatment of painful osteoporotic vertebral fractures, vertebroplasty demonstrated no beneficial effect in comparison to a sham procedure when assessed at multiple time intervals after treatment. Surprisingly, the data from these high level studies conflicts with much of the previous literature which had cited encouraging results. Both of these trials, however, confirm that pain from osteoporotic compression fractures substantially diminishes over a period of months. Future research wil hopefully delineate which patients benefit from these procedures. Spine care providers should carefully consider al of the literature when considering the appropriate use of vertebroplasty and kyphoplasty.

\section{Minimally Invasive Surgical Techniques}

Most current surgical techniques for the treatment of thoracolumbar trauma involve conventional open anterior or posterior exposures. These can be associated with postoperative complications such as infection, blood loss, ${ }^{52}$ scarring, adjacent segment, degeneration, or paraspinal muscle injury. ${ }^{59,60}$ Gejo and coworkers ${ }^{61}$ have demonstrated that the amount of injury to lumbar musculature is directly related to the duration of muscle retraction during posterior lumbar surgery. Patients undergoing long retraction times also reported postoperative lower back pain more frequently.

Minimally invasive surgical (MIS) techniques are increasingly being applied to the field of spine trauma in an attempt to minimize these negative consequences of conventional surgical techniques. Recent studies using MIS techniques to treat thoracolumbar fractures have suggested equivalent or favorable clinical outcomes when compared with open techniques. ${ }^{60,62}$ Potential drawbacks of MIS as a required to master the operative techniques, the longer operative times routinely associated with their utilization, as well as the necessity of intraoperative imaging with potentially increased radiation exposure to both the patient and the surgeon.

Over the past decade, several operative treatments for spine trauma have been applied using minimally invasive techniques. Anterior endoscopic decompression and stabilization has been reported as a safe and feasible treatment alternative to a conventional thoracotomy or thoracolumbar approach with the benefit of reduced approach-related morbidity, postoperative pain, and recovery time. ${ }^{62,63}$ Percutaneous tension band restoration or augmentation has been reported as a feasible technique for the treatment of stable burst or flexiondistraction injuries. ${ }^{60} \mathrm{~A}$ preliminary short-term study of 57 patients has demonstrated that reconstruction of the anterior column in thoracolumbar trauma using cages and minimally invasive techniques is a safe treatment. ${ }^{64}$ Unfortunately, definitive, multicenter, randomized trials have not been performed for any of the MIS treatments discussed to demonstrate superior clinical outcomes. The future of minimally invasive spine surgery appears promising as a means to minimize approachrelated morbidity, iatrogenic muscle injury, blood loss, and postoperative pain. Definitive, long-term studies will clearly define its evidence-based use as a treatment for thoracolumbar trauma in the future.

\section{Rehabilitation of Thoracolumbar Trauma}

Only a limited number of studies to date have provided evidence-based recommendations regarding the rehabilitative treatment of thoracolumbar spine trauma. The need for rigid bracing of anterior column compression fractures is currently a matter of debate. A retrospective study by Ohana and colleagues ${ }^{65}$ compared treating compression fractures by early ambulation with or without a Genuine Jewett Hyperextension brace (Florida Brace Corporation, Winter Park, FL). They found that thoracolumbar fractures with up to $30 \%$ height loss can be treated by early ambulation without a brace. In regard to postoperative bracing, it has been hypothesized that rigid braces do little to further stabilize the spine following thoracolumbar fixation. ${ }^{66}$ Apple and Perez $^{67}$ have recently demonstrated that the discontinuation of a Jewett brace or thoracic lumbar sacral orthosis at 4 weeks following operative fixation does not alter clinical outcome if the patient had a healthy spine prior to suffering a fracture. Moreover, the addition of a muscle-strengthening exercise program to the postoperative rehabilitation of thoracolumbar fractures has been shown to induce hypertrophy of the paraspinal musculature but has not been shown to correlate with pain relief. ${ }^{68}$ More comprehensive, randomized trials are needed to further refine the necessity of bracing and muscle strengthening following a thoracolumbar injury.

\section{Summary}

The management of thoracolumbar trauma is a controversial, rapidly evolving field. Many new diagnostic modalities and surgical treatments have been introduced in the past few 
decades, yet, until recently, most have not been scientifically validated using evidence-based protocols. The increasing importance of scientific and fiscal accountability will serve as an impetus for the organization of definitive, multicenter, randomized trials to provide quality evidence-based treatment recommendations in a field with historically underpowered research methodology.

\section{References}

1. Carr AJ. Evidence-based orthopaedic surgery: what type of research will best improve clinical practice? J Bone Joint Surg Br 2005;87:1593-1594

2. Sackett DL, Rosenberg WM, Gray JA, Haynes RB, Richardson WS. Evidence based medicine: what it is and what it isn't. BMJ 1996;312:71-72

3. Fisher CG, Wood KB. Introduction to and techniques of evidence-based medicine. Spine 2007;32(19, Suppl):S66-S72

4. Fisher CG, Noonan VK, Dvorak MF. Changing face of spine trauma care in North America. Spine 2006;31(11, Suppl):S2-S8, discussion S36

5. Bailey CS, Fisher CG, Dvorak MF. Type II error in the spine surgical literature. Spine 2004;29(10):1146-1149

6. Committee on Trauma, and Committee on Shock, Division of Medical Sciences, National Academy of Sciences/National Research Countil (US). Accidental Death and Disability: The Neglected Disease of Modern Society. Washington: National Academy of Sciences; 1966

7. West JG, Trunkey DD, Lim RC. Systems of trauma care: a study of two counties. Arch Surg 1979;114:455-460

8. Mullins RJ. A historical perspective of trauma system development in the United States. J Trauma 1999;47(3, Suppl):S8-S14

9. Cowley RA, Hudson F, Scanlan E, et al. An economical and proved helicopter program for transporting the emergency critically ill and injured patient in Maryland. J Trauma 1973;13(12):1029-1038

10. West JG, Cales RH, Gazzaniga AB. Impact of regionalization. The Orange County experience. Arch Surg 1983;118:740-744

11. Liberman M, Mulder DS, Lavoie A, Sampalis JS. Implementation of a trauma care system: evolution through evaluation. J Trauma 2004;56: 1330-1335

12. DeVivo MJ, Kartus PL, Stover SL, Fine PR. Benefits of early admission to an organised spinal cord injury care system. Paraplegia 1990;28 545-555

13. Smith M. Efficacy of specialist versus non-specialist management of spinal cord injury within the UK. Spinal Cord 2002;40:10-16

14. Hauswald M, Ong G, Tandberg D, Omar Z. Out-of-hospital spinal immobilization: its effect on neurologic injury. Acad Emerg Med 1998;5:214-219

15. Báez AA, Schiebel N. Evidence-based emergency medicine/systematic review abstract: is routine spinal immobilization an effective intervention for trauma patients? Ann Emerg Med 2006;47:110-112

16. Hauswald M, Braude D. Spinal immobilization in trauma patients: is it really necessary? Curr Opin Crit Care 2002;8:566-570

17. Verlaan JJ, van de Kraats EB, Dhert WJ, Oner FC. The role of 3-D rotationa X-ray imaging in spinal trauma. Injury 2005;36(Suppl 2):B98-B103

18. Sheridan R, Peralta R, Rhea J, Ptak T, Novelline R. Reformatted viscera protocol helical computed tomographic scanning allows conventional radiographs of the thoracic and lumbar spine to be eliminated in the evaluation of blunt trauma patients. J Trauma 2003;55:665-669

19. Keynan O, Fisher CG, Vaccaro A, et al. Radiographic measurement parameters in thoracolumbar fractures: a systematic review and consensus statement of the Spine Trauma Study Group. Spine 2006;31: E156-E165

20. Oner FC, Ramos LM, Simmermacher RK, et al. Classification of thoracic and lumbar spine fractures: problems of reproducibility: a study of 53 patients using CT and MRI. Eur Spine J 2002;11:235-245

21. Wood KB, Khanna G, Vaccaro AR, Arnold PM, Harris MB, Mehbod AA. As sessment of two thoracolumbar fracture classification systems as used by multiple surgeons. J Bone Joint Surg Am 2005;87:1423-1429

22. Bono CM, Vaccaro AR, Hurlbert RJ, et al. Validating a newly proposed classification system for thoracolumbar spine trauma: looking to the future of the thoracolumbar injury classification and severity score. Orthop Trauma 2006;20:567-572

23. Böhler L. Die Techniek Deknochenbruchbehandlung im Grieden und im Kreigen. Vienna: Verlag von Wilhem Maudrich;1930

24. Nicoll EA. Fractures of the dorso-lumbar spine. J Bone Joint Surg Am 1949;31:376-394

25. Holdsworth F. Fractures, dislocations, and fracture-dislocations of the spine. J Bone Joint Surg Am 1970;52:1534-1551

26. Louis R. Unstable fractures of the spine, III: Instability, A: Theories concerning instability. Rev Chir Orthop Repar Appar Mot 1977;63:423-425
27. Denis F. The three column spine and its significance in the classification of acute thoracolumbar spinal injuries. Spine 1983;8:817-831

28. Magerl F, Aebi M, Gertzbein SD, Harms J, Nazarian S. A comprehensive classification of thoracic and lumbar injuries. Eur Spine J 1994:3:184-201

29. McCormack T, Karaikovic E, Gaines RW. The load sharing classification of spine fractures. Spine 1994;19:1741-1744

30. Vaccaro AR, Zeiller SC, Hulbert RJ, et al. The thoracolumbar injury severity score: a proposed treatment algorithm. J Spinal Disord Tech 2005;18: 209-215

31. Vaccaro AR, Lehman RA Jr, Hurlbert RJ, et al. A new classification of thoracolumbar injuries: the importance of injury morphology, the integrity of the posterior ligamentous complex, and neurologic status. Spine 2005;30:2325-2333

32. Fassett DR, Politi R, Patel A, Brown Z, Vaccaro AR. Classification systems for acute thoracolumbar trauma. Curr Opin Orthop 2007:18:253-258

33. Harrop JS, Vaccaro AR, Hurlbert RJ, et al; Spine Trauma Study Group. Intrarater and interrater reliability and validity in the assessment of the mechanism of injury and integrity of the posterior ligamentous complex: a novel injury severity scoring system for thoracolumbar injuries. Invited submission from the Joint Section Meeting On Disorders of the Spine and Peripheral Nerves, March 2005. J Neurosurg Spine 2006; 4:118-122

34. Vaccaro AR, Baron EM, Sanfilippo J, et al. Reliability of a novel classification system for thoracolumbar injuries: the Thoracolumbar Injury Severity Score. Spine 2006;31(11, Suppl):S62-S69, discussion S104

35. Patel AA, Vaccaro AR, Albert TJ, et al. The adoption of a new classification system: time-dependent variation in interobserver reliability of the thoracolumbar injury severity score classification system. Spine 2007; 32:E105-E110

36. Audigé L, Bhandari M, Hanson B, Kellam J. A concept for the validation of fracture classifications. J Orthop Trauma 2005;19:401-406

37. McLain RF. Functional outcomes after surgery for spinal fractures: return to work and activity. Spine 2004;29:470-477, discussion Z6

38. Trivedi JM. Spinal trauma: therapy-options and outcomes. Eur J Radiol 2002;42:127-134

39. Hierholzer C, Buhren V, Woltmann A. Operative timing and management of spinal injuries in multiply injured patients. European Journal of Trauma and Emergency Surgery 2007;33:488-500

40. Rutges JPHJ, Oner FC, Leenen LPH. Timing of thoracic and lumbar fracture fixation in spinal injuries: a systematic review of neurological and clinical outcome. Eur Spine J 2007;16:579-587

41. Rechtine GR II. Nonoperative management and treatment of spinal injuries. Spine 2006;31(11, Suppl):S22-S27, discussion S36

42. Siebenga J, Leferink VJ, Segers MJ, et al. Treatment of traumatic thoracolumbar spine fractures: a multicenter prospective randomized study of operative versus nonsurgical treatment. Spine 2006;31:2881-2890

43. Wood K, Buttermann G, Mehbod A, et al. Operative compared with nonoperative treatment of a thoracolumbar burst fracture without neurological deficit: a prospective, randomized study. J Bone Joint Surg Am 2003;85-A:773-781

44. Yi L, Jingping B, Gele J, Baoleri X, Taixiang W. Operative versus non-operative treatment for thoracolumbar burst fractures without neurologica deficit. Cochrane Database Syst Rev 2006;(4):CD005079

45. Amar AP, Levy ML. Pathogenesis and pharmacological strategies for mitigating secondary damage in acute spinal cord injury. Neurosurgery 1999:44:1027-1039, discussion 1039-1040

46. Fehlings MG, Perrin RG. The timing of surgical intervention in the treatment of spinal cord injury: a systematic review of recent clinical evidence. Spine 2006;31(11, Suppl):S28-S35, discussion S36

47. La Rosa G, Conti A, Cardali S, Cacciola F, Tomasello F. Does early decompression improve neurological outcome of spinal cord injured patients? Appraisal of the literature using a meta-analytical approach. Spinal Cord 2004:42:503-512

48. Croce MA, Bee TK, Pritchard E, Miller PR, Fabian TC. Does optimal timing for spine fracture fixation exist? Ann Surg 2001;233:851-858

49. Kerwin AJ, Frykberg ER, Schinco MA, Griffen MM, Murphy T, Tepas JJ. The effect of early spine fixation on non-neurologic outcome. J Trauma 2005;58:15-21

50. Schinkel C, Frangen TM, Kmetic A, Andress HJ, Muhr G ; German Trauma Registry. Timing of thoracic spine stabilization in trauma patients: impact on clinical course and outcome. J Trauma 2006;61:156-160, discussion 160

51. Albert TJ, Kim DH. Timing of surgical stabilization after cervical and thoracic trauma. Invited submission from the Joint Section Meeting on Disorders of the Spine and Peripheral Nerves, March 2004. J Neurosurg Spine 2005;3:182-190

52. Verlaan JJ, Diekerhof $\mathrm{CH}$, Buskens E, et al. Surgical treatment of traumatic fractures of the thoracic and lumbar spine: a systematic review of the literature on techniques, complications, and outcome. Spine 2004;29:803-814

53. Truumees E, Hilibrand A, Vaccaro AR. Percutaneous vertebral augmentation. Spine J 2004;4:218-229 
54. Alvarez L, Alcaraz M, Pérez-Higueras A, et al. Percutaneous vertebroplasty: functional improvement in patients with osteoporotic compression fractures. Spine 2006;31:1113-1118

55. Hulme PA, Krebs J, Ferguson SJ, Berlemann U. Vertebroplasty and kyphoplasty: a systematic review of 69 clinical studies. Spine 2006;31: 1983-2001

56. Patel AA, Vaccaro AR, Martyak GG, et al. Neurologic deficit following percutaneous vertebral stabilization. Spine 2007;32:1728-1734

57. Buchbinder R, Osborne RH, Ebeling PR, et al. A randomized trial of vertebroplasty for painful osteoporotic vertebral fractures. N Engl J Med 2009; plasty for pa

58. Kallmes DF, Comstock BA, Haegerty PJ, et al. A randomized trial of vertebroplasty for osteoporotic spinal fractures. N Engl J Med 2009;361:269-279

59. Kawaguchi $Y$, Matsui $H$, Tsuji $H$. Back muscle injury after posterior lumbar spine surgery: a histologic and enzymatic analysis. Spine 1996;21: 941-944

60. Rampersaud YR, Annand N, Dekutoski MB. Use of minimally invasive surgical techniques in the management of thoracolumbar trauma: current concepts. Spine 2006;31:S96-102; discussion S104.

61. Gejo R, Matsui H, Kawaguchi Y, Ishihara H, Tsuji H. Serial changes in trunk muscle performance after posterior lumbar surgery. Spine 1999 24:1023-1028
62. Schultheiss M, Kinzl L, Claes L, Wilke HJ, Hartwig E. Minimally invasive ventral spondylodesis for thoracolumbar fracture treatment: surgical technique and first clinical outcome. Eur Spine J 2003;12:618-624

63. Khoo LT, Beisse R, Potulski M. Thoracoscopic-assisted treatment of thoracic and lumbar fractures: a series of 371 consecutive cases. Neurosurgery 2002;51(5, Suppl):S104-S117

64. Kossmann T, Rancan M, Jacobi D, Trentz O. Minimally invasive vertebral replacement with cages in thoracic and lumbar spine. Eur J Trauma 2001;27:292-300

65. Ohana N, Sheinis D, Rath E, Sasson A, Atar D. Is there a need for lumbar orthosis in mild compression fractures of the thoracolumbar spine?: A retrospective study comparing the radiographic results between early ambulation with and without lumbar orthosis. J Spinal Disord 2000; 13:305-308

66. Connolly PJ, Grob D. Bracing of patients after fusion for degenerative problems of the lumbar spine-yes or no? Spine 1998;23:1426-1428

67. Apple DF Jr, Perez M. Prospective study of orthotic use after operative stabilization of traumatic thoracic and lumbar fractures. Top Spinal Cord Inj Rehabil 2006;12:77-82

68. Kramer M, Dehner C, Katzmaier P, et al. Device-assisted muscle strengthening in the rehabilitation of patients after surgically stabilized vertebral fractures. Arch Phys Med Rehabil 2005;86:558-564 